\title{
PERTUMBUHAN DAN HASIL DUA KLON UBI JALAR PADA TINGGI BEDENGAN YANG BERBEDA
}

\author{
Haryuni, Adnan, Eko Fransisko \\ Universitas Pat Petulai \\ email: haryuni66@gmail.com
}

\begin{abstract}
Sweet potato is one of the staple food for some Indonesian society therefore sweet potato plants play an important role in the position of national food barns. This study aims to get the best bed height for two sweet potato plant clones. This research was conducted in the experimental garden of rejang lebong college of agricultural sciences. This research was conducted using a randomized block design (rcbd) with two factorials consisting of: first factor clone ( $k$ ) 2 types namely: $k 1=$ red sweet potatoes, $k 2=$ honey sweet potatoes. Second factor height of beds (b) 3 types namely: $b 1=20 \mathrm{~cm}, b 2=40 \mathrm{~cm}, b 3=60 \mathrm{~cm}$. The treatment was repeated three times so that there were 18 experimental units. Each experimental unit consist 3 beds. The results showed the best varieties are red sweet potato varieties and the best height of beds with $40 \mathrm{~cm}$ high beds.
\end{abstract}

Keywords: red sweet potatoes, honey sweet potatoes, clone, bed

Abstrak. Ubi jalar merupakan salah satu makanan pokok bagi sekelompok penduduk Indonesia, karena itu tanaman ubi jalar ikut memegang peranan penting di dalam posisi lumbung pangan nasional. Penelitian ini bertujuan untuk mendapatkan tinggi bedengan terbaik untuk dua klon tanaman ubi jalar. Penelitian ini dilakukan dikebun percobaan Sekolah Tinggi Ilmu Pertanian Rejang Lebong. Penelitian ini dilaksanakan dengan menggunakan rancangan acak kelompok (rak) dengan dua faktorial terdiri atas : faktor pertama klon (k) 2 jenis yaitu : $\mathrm{k}_{1}=$ ubi jalar merah, $\mathrm{k}_{2}=$ ubi jalar madu. Faktor kedua tinggi bedengan (b) 3 jenis yaitu: $\mathrm{b}_{1}=20 \mathrm{~cm}, \mathrm{~b}_{2}=40 \mathrm{~cm}, \mathrm{~b}_{3}=60 \mathrm{~cm}$. Dari perlakuan diulang empat kali sehingga terdapat 18 satuan percobaan. Setiap satu satuan percobaan terdiri atas 3 bedengan. Hasil penelitian menunjukkan varetas terbaik yaitu klon tanaman ubi jalar merah dan tinggi bedengan yang terbaik yaitu dengan tinggi bedengan $40 \mathrm{~cm}$.

Kata kunci: ubi jalar merah, ubi jalar madu, klon, bedengan

\section{PENDAHULUAN}

Ubi jalar (Ipomoea batatas L.) merupakan tanaman pangan yang mempunyai potensi besar untuk dikembangkan di Indonesia tanaman ini merupakan golongan umbi-umbian yang aslinya berasal dari Amerika Latin (Guwet, 2009). Selain sebagai salah satu bahan diversifikasi pangan yang ekonomis, ubi jalar juga memiliki kandungan gizi serta kandungan karbohidrat yang tinggi dibandingkan tanaman umbi-umbian lainya (Pertanian, 2013). Tanaman ubi jalar menunjukkan perkembangan yang sangat pesat (Wandana et al., 2012).

Kendala dan hambatan pada produksi ubi jalar antara lain disebabkan oleh teknik budidaya, pemilihan jenis, penerapan pola tanam yang kurang tepat dan proses distribusi hasil panen. Pada penelitian ini para petani menggunakan ukuran ketinggian bedengan dengan cara dengan pengalaman mereka sendiri sehingga hasil dari produksi ubi jalar kurang maksimal. Produksi ubi jalar sangat tergantung kepada jumlah dan laju asimilat kebagian bawah. Pertumbuhan tajuk memberikan kontribusi bagi pertumbuhan bagian bawah. Akan tetapi jika pertumbuhan tajuk lebih besar akan mengakibatkan ubi menjadi kecil. Oleh karena itu dibutuhkan altenatif jarak tanam yang paling sesuai untuk dua jenis ubi jalar agar ruang untuk pembentukan umbi cukup (Widodo et al., 2010).

Umumnya, para petani membuat bedengan atau guludan selebar 70-120 cm atau lebih, dan tinggi $20-30 \mathrm{~cm}$, dengan panjang bervariasi mengikuti arah lereng. Bedengan yang dibuat panjang searah lereng akan memperbesar erosi dan penghanyutan hara, karena tanah di dalam bedengan akan mengalami pengikisan dan penghanyutan oleh aliran permukaan pada saat hujan, 
sehingga akan menurunkan tingkat kesuburan dan produktivitas tanahnya (Kurnia et al., 2000). Guludan yang terlalu tinggi cenderung menyebabkan terbentuknya umbi berukuran panjang dan dalam sehingga menyulitkan pada saat panen. Sebaliknya, guludan yang terlalu dangkal dapat menyebabkan terganggunya pertumbuhan atau perkembangan ubi, dan memudahkan seranggan hama boleng atau lanas oleh Cylas sp (Setyawan, 2015).

Pupuk kandang juga sangat berperan penting dalam pertumbuhan tanaman ubi jalar dengan cara memperbaiki struktur tanah, karena menambah bahan organik (Suharno et al., 2010). Pupuk organik juga mempunyai manfaat dalam memberikan media bagi kehidupan mikroorganisme menguntungkan bagi kesuburan tanah dan mengurangi porostias pada tanah pasir dan membantu aerasi pada tanah lempung (Purba et al., 2018). Setiap penambahan pupuk organik juga dapat mendorong pembentukan umbi akan lebih baik (Agbede, 2010). Budidaya di bedengan meningkatkan bobot, panjang, dan diameter umbi , sedangkan budidaya di karung hanya meningkatkan jumlah umbi (Sugiartini et al., 2015). Hasil penelitian (Yoandari et al., 2017) menunjukkan perlakuan tinggi bedengan berpengaruh nyata terhadap pertambahan panjang tanaman 5 MST.

Penelitian ini bertujuan mendapatkan tinggi bedengan terbaik untuk dua klon tanaman ubi jalar.

\section{METODE}

\section{Bahan}

Kegiatan Penelitian telah dilaksanakan pada bulan Juni sampai Oktober 2019. Penelitian dilaksanakan di Lahan Percobaan STIPER-RL. Bahan yang digunakan ialah bibit setek pucuk ubi jalar klon ubi jalar madu dan klonubi jalar merah. Alat yang digunakan yaitu cangkul, pisau atau cutter, meteran, kertas label, papan nama, timbangan analitik, gembor dan alat tulis.

Penelitian ini dilaksanakan dengan menggunakan Rancangan Acak Kelompok (RAK) dengan dua faktorial terdiri atas : Faktor Pertama Klon (K) 2 Jenis yaitu : $\mathrm{K}_{1}=$ Ubi Merah $\mathrm{K}_{2}=$ Ubi Madu Faktor Kedua Tinggi Bedengan (B) 3 Jenis yaitu: $\mathrm{B}_{1}=20 \mathrm{~cm} \mathrm{~B}=40 \mathrm{~cm} \mathrm{~B}_{3}$ $=60 \mathrm{~cm}$. Pengamatan terhadap tanaman ubi jalar meliputi: Panjang tanaman $(\mathrm{cm})$, Jumlah umbi pertanaman (buah), Panjang umbi $(\mathrm{cm})$ Diameter umbi(mm), Bobot total umbi (g), Jumlah umbi per plot. Analisis data dilakukan dengan uji $\mathrm{F}$ dan apabila perlakuan menunjukkan pengaruh yang nyata maka analisis diteruskan dengan uji lanjut menggunakan uji Duncan Multiple Range Test (DMRT) pada taraf nyata 5\%.

\section{HASIL DAN PEMBAHASAN}

\section{Analisis Keragaman}

Masing-masing variabel memiliki respons yang berbeda terhadap klon tanaman, tinggi bedengan dan interaksi berpengaruh nyata terhadap pertumbuhan dan hasil tanaman.

\section{Pengaruh Klon Tanaman}

Pengaruh Klon Tanaman memiliki respons yang berbeda terhadap variabel yang diamati. Hasil penelitian menunjukkan bahwa klon tanaman ubi jalar merah menunjukkan hasil berpengeruh nyata terhadap semua variabel tanaman yang diamati, sedangkan klon tanaman ubi jalar madu tidak menunjukkan hasil terbaik pada variabel ubi jalar madu (Gambar 2).

Perlakuan klon tanaman tidak berpengaruh nyata terhadap semua variabel yang di amati kecuali, panjang umbi berpengaruh nyata. Perlakuan tinggi bedengan berpengaruh nyata terhadap semua variabel pengamatan kecuali tinggi tanaman. Interaksi klon tanaman dan tinggi bedengan semua variabel yang diamati tidak berpengaruh nyata (Tabel 1). 
Tabel 1. Hasil analisis varian (anava) taraf 5\% terhadap variabel yang diamati

\begin{tabular}{|c|c|c|c|c|c|c|}
\hline \multirow{3}{*}{$\begin{array}{l}\text { Variabel Pengamatan } \\
\text { Tinggi Tanaman }\end{array}$} & \multicolumn{6}{|c|}{ F-hitung } \\
\hline & \multicolumn{2}{|c|}{ Klon } & \multicolumn{2}{|c|}{ Tinggi Bedengan } & \multicolumn{2}{|c|}{ Interaksi } \\
\hline & 0,02 & ns & 0,30 & ns & 0,15 & $\mathrm{~ns}$ \\
\hline Jumlah Umbi Per Tanaman & 1,04 & ns & 4,27 & $*$ & 0,02 & $\mathrm{~ns}$ \\
\hline Panjang Umbi & 4,82 & * & 5,08 & * & 1,23 & $\mathrm{~ns}$ \\
\hline Diameter Umbi & 1,64 & ns & 7,09 & * & 3,26 & ns \\
\hline Bobot Total Umbi & 4,12 & ns & 7,53 & $*$ & 2,01 & $\mathrm{~ns}$ \\
\hline Jumlah Umbi Per Plot & 0,12 & ns & 7,42 & * & 0,64 & $\mathrm{~ns}$ \\
\hline
\end{tabular}

Keterangan: *berpengaruh nyata pada uji $\mathrm{F}$ taraf 5\%. ns: non-signifikan.

Klon tanaman ubi jalar madu pada variabel panjang umbi tidak menunjukkan hasil terbaik (Gambar 2), gambar diatas ini terlihat bahwa ubi jalar madu berbentuk bulat dan ubi jalar merah terlihat lebih panjang dari ubi jalar madu. Hal ini di karekan perakaran ubi jalar madu saat proses pengisian umbi terjadi melebar kesamping sehingga berbentuk bulat saat pengisian umbi sudah optimal sedangkan perekaran ubi jalar merah memanjang kearah bawah sehingga proses pemenuhan ubi terlihat lebih panjang dibandingkan dengan ubi jalar madu.

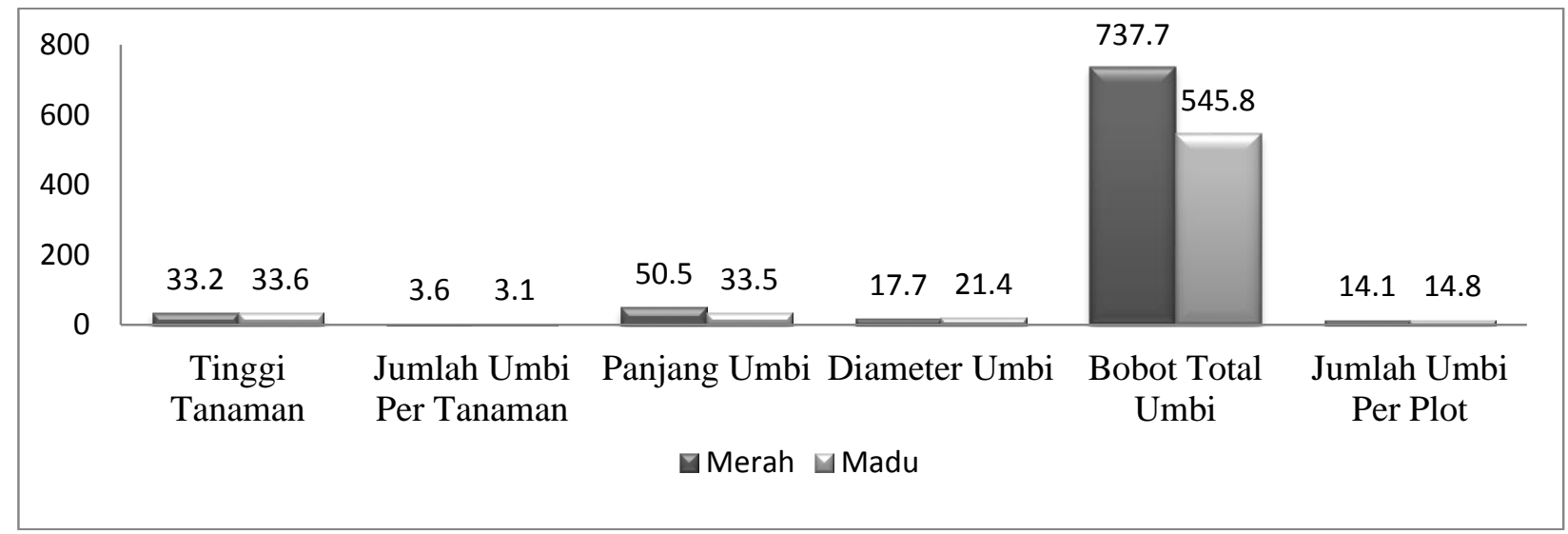

Gambar 1. Pengaruh klon tanaman ubi jalar merah dan ubi jalar madu terhadap variabel yang diamati

Ubi adalah organ tanaman yang merupakan modifikasi akar sebagai tempat akumulasi fotosintat. Dari sini bisa kita identifikasi ada perbedaan karakter morfologi dari akar dan daun antara varietas ubi merah dan ubi madu sehingga berpengaruh terhadap panjang ubi. 
Akar penyerap hara berfungsi untuk menyerap unsur-unsur hara yang ada dalam tanah, sedangkan akar lumbung berfungsi sebagai tempat untuk menimbun sebagian makanan yang nantinya akan terbentuk umbi.

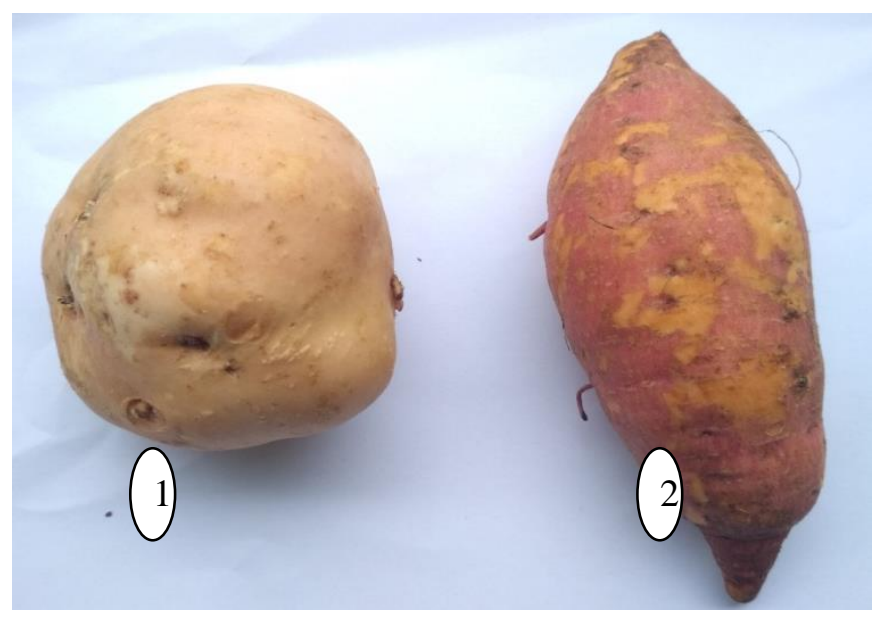

Gambar 2. $\mathrm{U}_{1}$ Ubi jalar madu dan $\mathrm{U}_{2} \mathrm{Ubi}$ jalar merah

Tanaman ubi jalar dapat tumbuh pada keasaman tanah $(\mathrm{pH})$ 4,5-7,5, tetapi yang optimal untuk pertumbuhan umbi pada $\mathrm{pH}$ 5,5-7. Sewaktu muda tanaman membutuhkan kelembaban tanah yang cukup. Ada 2 tipe akar ubi jalar yaitu akar penyerap hara di dalam tanah dan akar lumbung atau umbi. Akar penyerap hara berfungsi untuk menyerap unsur-unsur hara yang ada dalam tanah, sedangkan akar lumbung berfungsi sebagai tempat untuk menimbun sebagian makanan yang nantinya akan terbentuk umbiKedalaman akar tidak lebih dari $45 \mathrm{~cm}$. Daun merupakan pabrik fotosintesis, bisa jadi karakteristik morfologi daun yang berbeda mampu mempengaruhi fotosintat yang dihasilkan yang pada akhirnya mampu memberikan hasil yang berbeda nyata pada panjang ubi. Fotosintesis yang sempurna dapat pula menghasilkan fotosintat yang baik pula untuk prosese pertumbuhan dan pembentukan umbi dengan baik. Ubi jalar adalah tanaman tropis dan subtropis yang dapat beradaptasi dengan daerah beriklim lebih memberikan suhu rata-rata tidak turun di bawah $20^{\circ} \mathrm{C}$ dan suhu minimum tinggal di atas $15{ }^{\circ} \mathrm{C}$, pada penelitian ini suhu di daerah kabupaten rejang lebong sangat bagus untuk pertumbuhan ubi jalar. Menurut (Kathabwalika et al., 2013) pada dataran menengah ubi jalar yang ditanam mampu meningkat produksi dikarenakan faktor genotipenya mendukung. Selain itu faktor lingkungan juga menjadi faktor pendukung terhadap peningkatan produksi ubi jalar.

\section{Pengaruh Tinggi Bedengan}

Pengaruh Tinggi Bedengan sangat berpengaruh nyata terhadap semua variabel yang diamati. 
Tabel 2. Pengaruh tinggi bedengan tanaman ubi jalar merah dan ubi jalar madu terhadap variabel yang diamati

\begin{tabular}{|c|c|c|c|c|c|c|}
\hline \multirow{2}{*}{ Variabel Pengamatan } & \multicolumn{6}{|c|}{ Tinggi Bedengan } \\
\hline & \multicolumn{2}{|c|}{$20 \mathrm{~cm}$} & \multicolumn{2}{|c|}{$40 \mathrm{~cm}$} & \multicolumn{2}{|c|}{$60 \mathrm{~cm}$} \\
\hline Tinggi Tanaman & 35,0 & $\mathrm{a}$ & 32,9 & $\mathrm{a}$ & 32,3 & $\mathrm{a}$ \\
\hline Jumlah Umbi Per Tanaman & 3.4 & $a b$ & 4,4 & $\mathrm{a}$ & 2,3 & $\mathrm{~b}$ \\
\hline Panjang Umbi & 42,1 & $\mathrm{ab}$ & 57,0 & $\mathrm{a}$ & 26,8 & $\mathrm{~b}$ \\
\hline Diameter Umbi & 19,2 & $a b$ & 26,3 & $\mathrm{a}$ & 13,1 & $\mathrm{~b}$ \\
\hline Bobot Total Umbi & 654,1 & $a b$ & 860 & $a$ & 411,2 & $b$ \\
\hline Jumlah Umbi Per Plot & 13,6 & $\mathrm{~b}$ & 20,0 & $\mathrm{a}$ & 9,83 & $b$ \\
\hline
\end{tabular}

Keterangan : Angka-angka yang diikuti oleh huruf yang sama pada kolom yang sama berbeda tidak nyata pada uji Duncan Multiple's Range Test (DMRT) taraf 5\%.

Hasil penelitian menunjukkan bahwa tinggi bedengan $40 \mathrm{~cm}$ menunjukkan hasil tinggi terhadap semua variabel yang diamati, kemudian hasil terbaik berikutnya menujukkan bahwa tinggi bedengan $60 \mathrm{~cm}$ menunjukkan hasil lebih baik dibandingkan tinggi bedengan $20 \mathrm{~cm}$ menunjuk hasil tidak baik hanya pada variabel tinggi tanaman. Beberapa variabel pengamatan pada ketinggian bedengan $60 \mathrm{~cm}$ secara angka menunjukkan nilai yang lebih tinggi dibandingkan dengan beberapa variabel pengamatan pada ketinggian bedengan $20 \mathrm{~cm}$, akan tetapi secara statistik menunjukkan hasil yang tidak berbeda nyata, sehingga tidak dapat dikatakan perlakuan bedengan $60 \mathrm{~cm}$ menunjukkan hasil terbaik dibandingkan perlakuan bedengan $20 \mathrm{~cm}$ (Tabel 2). Gambar 3 merupakan gambar tanaman klon ubi jalar madu dan tanaman ubi jalar merah.
Hasil Penelitian Widodo et. al, (2010) bahwa di lahan sawah, cara budidaya dengan membuat gulud besar dan tinggi secara bertahap lebih efektif dan efisien dibandingkan cara tradisional yang memerlukan turun gulud dan membumbun kembali. Umumnya, para petani membuat bedengan atau guludan selebar $70-120 \mathrm{~cm}$ atau lebih, dan tinggi $20-30 \mathrm{~cm}$, dengan panjang bervariasi mengikuti arah lereng. Bedengan yang dibuat panjang searah lereng akan memperbesar erosi dan penghanyutan hara, karena tanah di dalam bedengan akan mengalami pengikisan dan penghanyutan oleh aliran permukaan pada saat hujan, sehingga akan menurunkan tingkat kesuburan dan produktivitas tanahnya (Kurnia et al, 2000). 


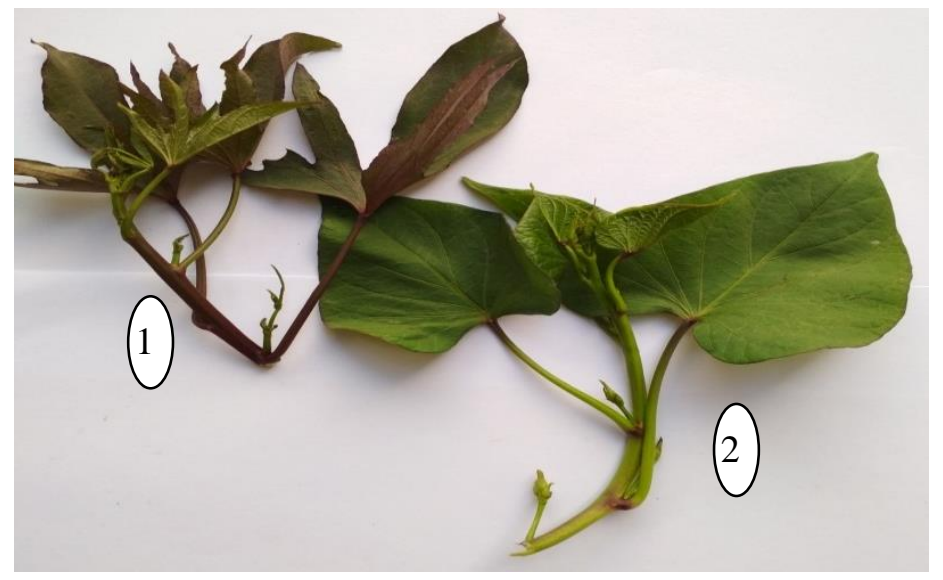

Gambar 3. Klon tanaman ubi jalar madu (1) dan klon tanaman ubi jalar merah(2)

Hal yang paling penting diperhatikan dalam pembuatan guludan adalah ukuran tinggi tidak melebihi $40 \mathrm{~cm}$. Guludan yang terlalu tinggi cenderung menyebabkan terbentuknya umbi berukuran panjang dan dalam sehingga menyulitkan pada saat panen. Sebaliknya, guludan yang terlalu dangkal dapat menyebabkan terganggunya pertumbuhan atau perkembangan ubi, dan memudahkan seranggan hama boleng atau lanas oleh Cylas sp (Setyawan, 2015). Hasil penelitian ini juga menunjukkan bahwa tinggi bedengan $40 \mathrm{~cm}$ menunjukkan hasil terbaik terhadap semua variabel yang diamati (Tabel 3). Berbeda dengan hasil penelitian (Murda \& Soelistyono, 2019) yang melakukan penelitian pada tanaman terung unggu tinggi bedengan $20 \mathrm{~cm}$ menunjukkan nilai pertumbuhan dan hasil terung unggu yang lebih baik pada hampir seluruh parameter.

\section{Interaksi Klon Tanaman dan Tinggi Bedengan}

Berdasarkan hasil analisis statistik pada Tabel 1 diketahui bahwa interaksi antara perlakuan klon tanaman dan tinggi bedengan adalah non signifikan (tidak berbeda nyata). Dari hasil penelitian klon yang baik yaitu klon tanaman ubi jalar merah. Bedengan adalah gundukan tanah yang sengaja dibuat oleh petani untuk menanam tanaman pangan dengan lebar dan tinggi tertentu, dan diantara dua bedengan dipisahkan oleh saluran atau parit drainase yang berguna untuk mengalirkan air agar aerasi tanah atau kelembapan tanah dalam bedengan tetap terjaga. bedengan yg terbaik yaitu dengan ketinggi bedengan $40 \mathrm{~cm}$. Direkomendasikan kepada para petani untuk budidaya tanaman klon ubi jalar merah sabaiknya menggunakan tinggi bedengan dengan ketinggian $40 \mathrm{~cm}$.

\section{SIMPULAN}

Klon yang terbaik pada penelitian ini yaitu klon ubi jalar merah, tinggi bedengan yang terbaik untuk tanaman ubi jalar adalah dengan tinggi bedengan 40 $\mathrm{cm}$ dan Interaksi perlakuan klon tanaman ubi jalar dan tinggi bedengan tidak berpengaruh nyata terhadap seluruh parameter pengamatan. Saran perlu di lakukan peneletian ke tahap selajutnya dengan menambahkan klon tanaman ubi

\section{DAFTAR PUSTAKA}

Agbede, T. M. (2010). Tillage and fertilizer effects on some soil properties, leaf nutrient concentrations, growth and sweet potato yield on an Alfisol in southwestern Nigeria. Soil and Tillage Research, $110(1)$, 25-32. https://doi.org/10.1016/j.still.2010.06.003

Guwet, H. (2009). Karakteristik Ukuran Umbi dan Bentuk Umbi Plasma Nutfah Ubi Jalar. Balitan Plasma Nutfah:Badan Penelitian Bioteknologi dan Sumber 
Daya Genetik.

Kathabwalika, D. M., Chilembwe, E. H. C., Mwale, V. M., Kambewa, D., \& Njoloma, J. P. (2013). Plant growth and yield stability of orange fleshed sweet potato (Ipomoea batatas) genotypes in three agro-ecological zones of Malawi. Int. Res. J. Agric. Sci. Soil Sci., 3(11), 383-392.

Kurnia, U., Sulaeman, Y., \& Muti, K. A. (2000). Potensi dan pengelolaan lahan kering dataran tinggi (pp. 227-245). Badan Penelitian dan Pengembangan Pertanian.

Murda, C. S., \& Soelistyono. (2019). Kajian Tinggi Bedengan dan Kerapatan Tanaman terhadap Pertumbuhan dan Hasil Tanaman Terung Ungu. Jurnal Produksi Tanaman, 7(4), 1278-1287.

Pertanian, D. J. T. P. K. (2013). Pedoman Teknis Pengelolaan dan Produksi Ubi Jalar dan Aneka Umbi.

Purba, J. H., Parmila, I. P., \& Sari, K. K. (2018). Pengaruh Pupuk Kandang Sapi dan Jarak Tanam terhadap Pertumbuhan dan Hasil Kedelai (Glycine max L. Merrill) Varietas Edamame. Agro Bali: Agricultural Journal, 1(2), 69-81.

Setyawan, B. (2015). Budidaya Umbi-umbian Padat Nutrisi. Pustaka Baru Press.

Sugiartini, E., Ikrarwati, I., Yusuf, M., \& Restouno, J. (2015). Keragaan Beberapa Varietas Ubi Jalar Mendukung Program Diversifikasi Pangan di DKI Jakarta. Prosiding Seminar Hasil Penelitian Tanaman Aneka Kacang Dan Umbi.

Suharno, A., Rachman, K., \& Apsari, S. R. (2010). Pengaruh Jenis Pupuk Organik Terhadap Pertumbuhan dan Produksi Ubi Jalar (ipomea batatas L.). Jurnal Agriekstensia, 9(2), 118-124.

Wandana, S., Hanum, C., \& Sipayung, R. (2012). Pertumbuhan dan Hasil Ubi Jalar dengan Pemberian Pupuk Kalium dan Triakontanol. Jurnal Online Agroekoteknologi, 1(1), 199-211.

Widodo, Y., Prasetiaswati, N., Santosa, G., \& Suprapto. (2010). Teknologi produksi ubi jalar di lahan sawah mencapai produksi tinggi. Laporan Teknik. Balai Penelitian Tanaman Kacang-kacangan dan Umbiumbian. Badan Litbang Pertanian.

Yoandari, Lahay, R. R., \& Rahnawati, N. (2017). Respons Pertumbuhan dan
Produksi Ubi Jalar (Ipomoea batatas L.) terhadap Tinggi Bedengan dan Dosis Pupuk Kandang Ayam. Jurnal Agroekoteknologi Universitas Sumatera Utara, 5(1), 33-41. 